\title{
Effect of dynamic cardiomyoplasty on phasic coronary arterial flow velocity in canine hearts
}

The usefulness of dynamic cardiomyoplasty has been demonstrated repeatedly, both experimentally and clinically. Although clinical applications of dynamic cardiomyoplasty to ischemic heart disease have been reported, its effect on the coronary blood flow has never been discussed. Therefore, we tested the hypothesis that dynamic cardiomyoplasty might adversely affect coronary arterial blood flow through compression of the coronary arteries during systolic skeletal muscular contraction and incomplete relaxation of the skeletal muscle flap during diastole. Dynamic cardiomyoplasty was performed in seven mongrel dogs with the use of a left latissimus dorsi muscle flap, paced synchronously with the $\mathbf{R}$ wave of the electrocardiogram. A 3F Doppler catheter was placed in the left main trunk of the coronary artery to assess the instantaneous changes of coronary flow velocity by fast Fourier transformation analysis. We compared systolic and diastolic properties during assisted versus unassisted cardiac cycles by calculating the peak velocity and the time-velocity integral. During assisted cardiac cycles, a significant enhancement of coronary arterial blood flow velocity was demonstrated by significant increases in both systolic and diastolic peak velocity $(26.9 \% \pm 6.5 \%, p<0.005$; $4.0 \% \pm 1.6 \%, p<0.05$, respectively) and time-velocity integral $(20.9 \% \pm 4.8 \%, p<0.05$; $10.0 \% \pm 4.6 \%, p<0.05$, respectively). Enhancement of coronary arterial blood flow velocity was associated with an increase in mean aortic pressure $(16.4 \% \pm 1.3 \%, p<0.005)$ and descending aortic flow $(67.5 \% \pm 5.3 \%, p<0.005)$. Also, the improved systolic coronary arterial blood flow velocity was consistent with an increase in systolic aortic pressure $(15.8 \% \pm 1.5 \%, p<0.005)$, and enhancement of diastolic coronary arterial blood flow velocity was associated with an increase in diastolic aortic pressure $(8.6 \% \pm 2.3 \%, p<0.01)$. We concluded that coronary arterial blood flow velocity was increased by the enhancement of cardiac function as a result of dynamic cardiomyoplasty, leading to an increase of coronary perfusion pressure and cardiac output. ( $J$ ThORaC Cardiovasc Surg 1994;108:609-15)

Takuro Tsukube, MD, Masayoshi Okada, MD, Tomoichiro Mukai, MD, Mohammed A. Kashem, MD, and Toshiaki Ota, MD, Kobe, Japan

$\mathrm{D}$ namic cardiomyoplasty is a relatively new surgical procedure in which a skeletal muscle graft, which has been sequentially electrostimulated to fatigue-resistance, is applied to the myocardium and trained to contract in synchrony with the heart. Since the first report by Car-

From the Department of Surgery, Division II, School of Medicine, Kobe University, Kobe, Japan.

Presented in part at Sixty-fourth Scientific Sessions of the American Heart Association, November 1991, Anaheim, Calif.

Received for publication Oct. 1, 1993.

Accepted for publication May 10, 1994.

Address for reprints: Takuro Tsukube, MD, Department of Surgery, Division II, School of Medicine, Kobe University, 7-5-2 Kusunokicho, Chuou-ku, Kobe 650, Japan.

Copyright ${ }^{\circledR} 1994$ by Mosby-Year Book, Inc.

$0022-5223 / 94 \$ 3.00+0 \quad \mathbf{1 2} / \mathbf{1} / \mathbf{5 7 9 9 6}$ pentier and Chachques ${ }^{1}$ in 1985 , dynamic cardiomyoplasty has been used as a reinforcement cardiomyoplasty for ischemic or idiopathic dilated cardiomyopathy and as a substitute cardiomyoplasty for left ventricular (LV) aneurysms or LV tumors. ${ }^{2-4}$

Theoretically, dynamic cardiomyoplasty could be applied to cardiac contractile assistance and limitation of cardiac dilatation. ${ }^{5}$ The procedure also could potentially increase longevity by preventing the further increase in systolic and diastolic wall tension and arresting cardiac dilatation. ${ }^{5}$ Although dynamic cardiomyoplasty has been shown to improve systolic function and correct diastolic dysfunction in severe myocardial failure, ${ }^{6,7}$ its hemodynamic effects on coronary arterial blood flow have not been thoroughly characterized. We postulate that dynamic cardiomyoplasty may adversely affect coronary 


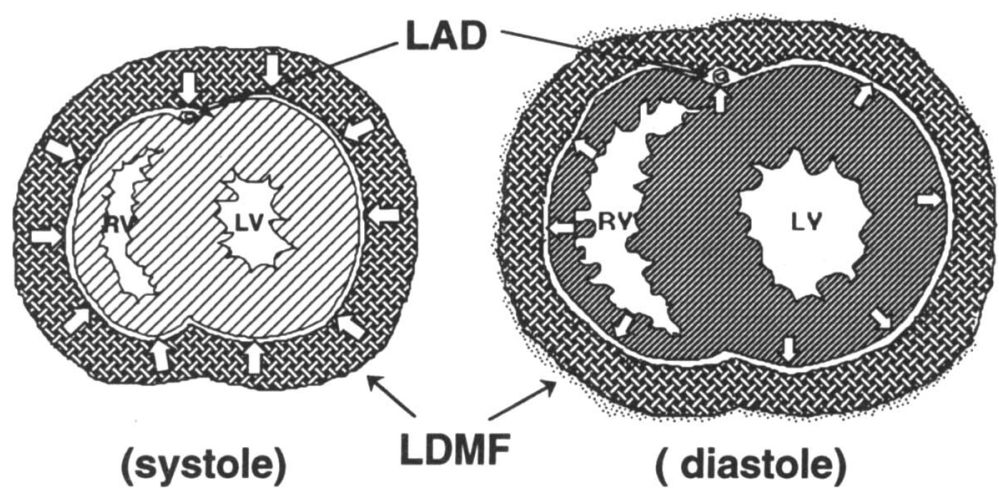

Fig. 1. Cross-sectional representation of the dynamic cardiomyoplasty: The coronary blood flow may be adversely affected by causing compression of the coronary arteries at skeletal muscle contraction in systole (left, white arrows) and incomplete relaxation of the skeletal muscle wrap in diastole (right, white arrows). $L V$, left ventricle; $R V$, right ventricle; $L A D$, left anterior descending artery; $L D M F$, latissimus dorsi muscle flap.

arterial blood flow by systolic compression of the coronary arteries and incomplete skeletal muscle relaxation during diastole (Fig. 1). A decrement in coronary arterial blood flow during dynamic cardiomyoplasty would cast doubt on the advisability of using this procedure for ischemic myocardial failure.

\section{Materials and methods}

Seven mongrel dogs of both sexes, weighing 12 to $18 \mathrm{~kg}$, were used in this study. All animals received humane care in compliance with the "Principles of Laboratory Animal Care" formulated by the National Society for Medical Research and the "Guide for the Care and Use of Laboratory Animals" prepared by the National Institutes of Health (NIH Publication No. 86-23, revised 1985). Each animal was anesthetized and prepared for the following sterile surgical procedures. General anesthesia was induced with ketamine hydrochloride $(5 \mathrm{mg} / \mathrm{kg})$ and thiamylal sodium $(30 \mathrm{mg} / \mathrm{kg})$ and was maintained with doses of sodium pentobarbital given intravenously as needed. Endotracheal intubation and positive-pressure mechanical ventilation (MA-1, Acoma Inc., Tokyo, Japan) were performed. Through a median neck incision, an arterial catheter was introduced into the ascending aorta via the right carotid artery for pressure monitoring.

Experimental preparation. With the dog in the right lateral decubitus position, the left latissimus dorsi muscle was dissected free from all attachments except for its thoracodorsal neuroviascular pedicle. A left anterior thoracotomy was made through the second intercostal space, and a 2 to $3 \mathrm{~cm}$ section of the second rib was resected. The latissimus dorsi muscle flap was then brought into the left hemithorax and anchored to the chest wall by suturing the proximal tendon (humeral insertion) around the third rib. Unipolar electrodes (model 6500, Medtronic Corp., Minneapolis, Minn.) were woven around the thoracodorsal nerve and into the midportion of the latissimus dorsi muscle flap. A second thoracotomy was then made through the left fifth intercostal space, and the heart was stspended in a pericardial cradle. An LV catheter was inserted through the LV apex. The electrocardiogram, blood pressure, and LV pressure were monitored by a Cath Lab Recording System (RMP-6004, Nihon-Kohden Inc., Tokyo, Japan). The descending thoracic aorta was also dissected free to allow the placement of an electromagnetic flowmeter (MFV-1200, Nihon Kohden Inc.).

Instrumentation. A 3F 20-MHz Doppler ultrasonic catheter (DC-201, Catalog No. 822-1088, Millar Instruments, Inc., Houston, Tex.) was inserted retrogradely through the first branch of left descending artery, and the tip of the catheter was placed at the origin of the left descending coronary artery (Fig. 2). The coronary blood flow toward the catheter tip was measured at a sampling point 3 to $4 \mathrm{~mm}$ from the tip. The catheter was connected to a $20 \mathrm{MHz}$ Doppler system (MDV-20, Millar Instruments, Inc.) and the power spectrum of the signals was analyzed by the fast Fourier transformation method using a fast Fourier transformation analyzer (SSH-140A, Tohshiba Medical Inc., Tokyo, Japan).

After placement of the catheter into the coronary artery, an acute myocardial infarction was induced by ligation of several branches of the left descending coronary artery. The latissimus dorsi muscle flap was then wrapped around both the left and right ventricles and fixed with interrupted 3-0 Prolene sutures (Ethicon, Inc., Somerville, N.J.). In a clockwise fashion, the proximal muscle segment was secured to the lateral LV wall, the middle segment to the inferoposterior aspect of the heart plus the right ventricular wall, and the distal segment to the anterior right ventricular wall.

Stimulation protocol. The stimulating leads were connected to an external $\mathbf{R}$ wave-synchronous stimulator (cardiac stimulator model BC-03, Fukuda Densi Inc., Tokyo, Japan), which was programmed to deliver burst stimuli synchronously with cardiac systole. The pacemaker was set to the following parameters: DDD mode, atrioventricular interval 10 to 100 msec, cardiac sensitivity 0.5 to $1.5 \mathrm{mV}$, muscular burst duration 160 to $200 \mathrm{msec}$, muscular burst frequency $50 \mathrm{~Hz}$, cardiac pulse amplitude 2.0 to $5.0 \mathrm{~V}$, and synchronization mode $1: 2$ for heart rate less than 100 pulses $/$ min and $1: 3$ for heart rate less than 200 pulses/min.

Stimulation was limited to brief periods because the skeletal muscle flap was not transformed before this experiment. During effective assisted cardiac cycles, functional data, including 
aortic blood pressure, LV pressure, blood flow of the thoracic descending aorta, and coronary arterial blood flow, were observed and recorded for 15 - to 25 -second periods. ${ }^{8}$

Evaluation of coronary arterial blood flow. Coronary arterial blood flow was evaluated by calculation of the systolic peak velocity, the systolic time-velocity integral (TVIs), the percent systolic fraction (\%SF), the diastolic peak velocity, the diastolic time-velocity integral (TVId), and the percent diastolic fraction (\%DF) (Fig. 3). lows:

The \%SF and the \%DF were calculated by equations as fol-

$\% \mathrm{SF}=\mathrm{TVIs} /(\mathrm{TVIs}+\mathrm{TVId}) \times 100 \%$

$\%$ DF $=$ TVId $/($ TVIs + TVId $) \times 100 \%$

Statistical analysis. Statistical analyses were performed with a statistical program (Statworks, Cricket Software, Inc. Philadelphia, Pa.). All values are expressed as the mean \pm standard error of the mean. A paired $t$ test was used to assess differences in coronary arterial flow velocity, LV pressure, aortic pressure, and aortic blood flow during assisted versus unassisted cardiac cycles. Differences were considered significant when $p<0.05$.

\section{Results}

After ligation of the branches of the left anterior descending coronary artery, LV systolic pressure, aortic systolic pressure, and aortic flow were depressed to $84.6 \pm 3.8 \mathrm{~mm} \mathrm{Hg}, 81.0 \pm 3.4 \mathrm{~mm} \mathrm{Hg}$, and $5.3 \pm 0.6$ $\mathrm{ml} /$ beat, respectively. Table I summarizes the hemodynamic changes that occurred with cardiac assistance by the skeletal muscle flap. Dynamic cardiomyoplasty significantly increased peak LV pressure and peak aortic pressure by $15.6 \% \pm 2.1 \%$ and $15.8 \% \pm 1.5 \%$, respectively, whereas descending aortic flow increased by $67.5 \% \pm 5.3 \%$. These increases were primarily due to the augmentation of cardiac function as a result of systolic muscular assistance. Diastolic aortic pressure also increased by $8.6 \% \pm 2.3 \%$. However, there was no significant increase in LV end-diastolic pressure $(-4.0 \% \pm 4.3 \%$, no significant difference). As a result of both systolic and diastolic aortic pressure increases, mean aortic pressure increased significantly by $16.4 \% \pm 1.3 \%$.

Table II summarizes the changes of coronary blood flow velocity that occurred as a result of the muscle flap. A significant enhancement of coronary arterial blood flow velocity was demonstrated by significant increases in both systolic and diastolic peak velocity $(26.9 \pm 6.5 \%$, $p<0.005 ; 4.0 \% \pm 1.6 \%: p<0.05$, respectively) and time velocity integral $(20.9 \% \pm 4.8 \%, p=0.005$; $10.0 \% \pm 4.6 \%, p<0.05$, respectively). Enhancement of coronary arterial blood flow velocity was associated with an increase in mean aortic pressure from $59.9 \pm 2.0 \mathrm{~mm}$ $\mathrm{Hg}$ to $69.6 \pm 2.3 \mathrm{~mm} \mathrm{Hg}(16.4 \% \pm 1.3 \%, p<0.005)$. Also, the improved systolic coronary arterial blood flow velocity was consistent with the increase of peak aortic pressure and cardiac output. Enhancement of diastolic

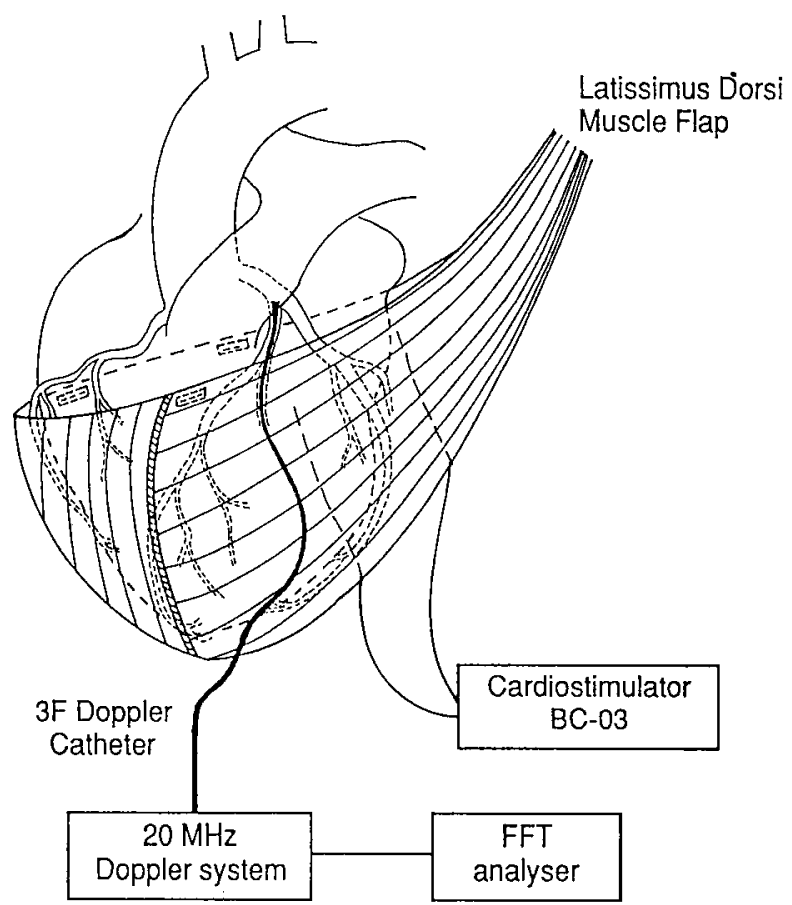

Fig. 2. Experimental preparation: A 3 F $20-\mathrm{MHz}$ Doppler ultrasonic catheter was placed at the origin of the left descending coronary artery inserted retrogradely through the first branch of left descending artery. The coronary blood flow toward the catheter tip was measured at a sampling point 3 to $4 \mathrm{~mm}$ from the tip. The catheter was connected to a $20 \mathrm{MHz}$ Doppler system and the power spectrum of the signals was analyzed by the fast Fourier transformation $(F F T)$ method with an FFT analyzer. Left latissimus dorsi muscle flap was then wrapped around both the left and right ventricles in a clockwise fashion. Unipolar electrodes were woven around the thoracodorsal nerve and into the midportion of latissimus dorsi muscle flap. These leads were connected to an external $\mathrm{R}$ wave-synchronous stimulator (cardiac stimulator BC-03).

coronary arterial blood flow velocity was associated with an increase in diastolic aortic pressure $(8.6 \% \pm 2.3 \%$, $p<0.01)$. When diastolic aortic pressure increases, coronary perfusion pressure, which is pressure gradient between aorta and coronary sinus, increases. ${ }^{9,} 10$ These results demonstrated that coronary arterial blood flow velocity was increased during assisted cardiac cycles. An increase of percent systolic fraction and a decrease of percent diastolic fraction were also recognized. The enhancement of coronary arterial blood flow velocity in systole was superior to that in diastole.

\section{Discussion}

Since Kantrowitz and Mckinnon ${ }^{11}$ and Nakamura and Glenn ${ }^{12}$ attempted to apply the skeletal muscle for 


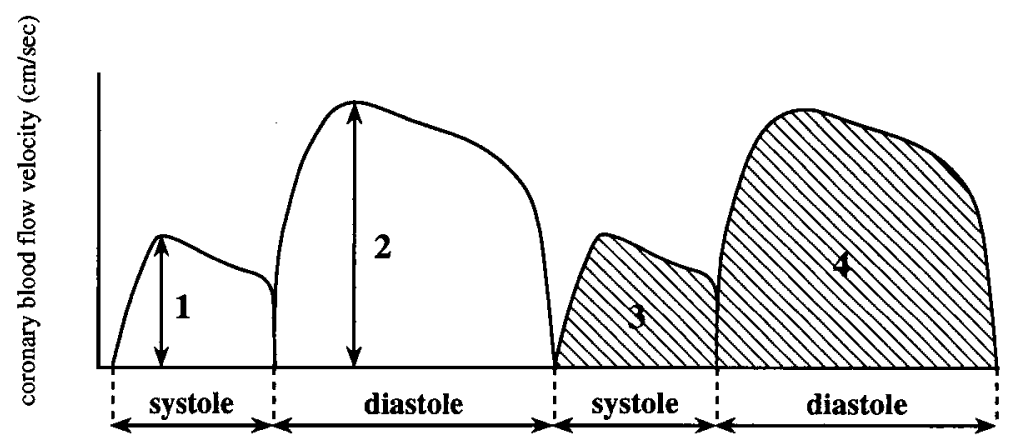

Fig. 3. Parameters of the coronary arterial blood flow velocity. 1, Peak systolic velocity $(\mathrm{cm} / \mathrm{sec})$. 2, Peak diastolic velocity $(\mathrm{cm} / \mathrm{sec}) .3$, Systolic time-velocity integral $(\mathrm{cm}) .4$, Diastolic time-velocity integral $(\mathrm{cm})$.

Table I. Hemodynamic data

\begin{tabular}{|c|c|c|c|c|c|c|}
\hline \multirow[b]{2}{*}{$D C M P$} & \multicolumn{2}{|c|}{ LV pressure $(\mathrm{mm} \mathrm{Hg})$} & \multicolumn{3}{|c|}{ Aortic pressure $(\mathrm{mm} \mathrm{Hg})$} & \multirow[b]{2}{*}{$\begin{array}{c}\text { Descending aortic } \\
\text { flow (ml/beat) }\end{array}$} \\
\hline & $\begin{array}{c}\text { Peak } \\
\text { systole }\end{array}$ & End-diastole & $\begin{array}{c}\text { Peak } \\
\text { systole }\end{array}$ & Mean & Diastole & \\
\hline Off & $84.6 \pm 3.8$ & $8.4 \pm 0.6$ & $81.0 \pm 3.4$ & $59.9 \pm 2.0$ & $49.4 \pm 1.3$ & $5.3 \pm 0.6$ \\
\hline On & $97.1 \pm 3: 4$ & $7.9 \pm 0.3$ & $93.8 \pm 4.1$ & $69.6 \pm 2.3$ & $53.4 \pm 1.4$ & $8.9 \pm 1.4$ \\
\hline Percent change & $15.6 \pm 2.1$ & $-4.0 \pm 4.3$ & $15.8 \pm 1.5$ & $16.4 \pm 1.3$ & $8.6 \pm 2.3$ & $67.5 \pm 5.3$ \\
\hline$p$ & $<0.005$ & NS & $<0.005$ & $<0.005$ & $<0.01$ & $<0.005$ \\
\hline
\end{tabular}

All values are represented as mean \pm standard error of the mean. $D C M P$, Dynamic cardiomyoplasty; percent change, percent changes from the unstimulated value. Statistical analysis by a paired $t$ test; $N S$, not significant.

mechanical cardiac support and Salmons and Sreter $^{13}$ discovered that low-frequency stimulation would result in total transformation of the muscle fiber type, the hemodynamic effects of dynamic cardiomyoplasty have been extensively investigated in experimental studies. ${ }^{14-18}$ Improvement of $\mathrm{LV}$ performance has been demonstrated to occur when a muscle flap is wrapped around the ventricular wall and induced to contract synchronously with the heart in the presence of both acute myocardial dysfunction ${ }^{19,20}$ and chronic dilated cardiomyopathy. ${ }^{8}$ The beneficial effects of this procedure were concluded to result from structural reinforcement of the LV wall, prevention of further dilatation of the failing heart, augmentation of cardiac performance, and reduction of myocardial oxygen consumption. ${ }^{8}$

Although about 200 patients have now undergone this procedure around the world for the treatment of ischemic or idiopathic dilated cardiomyopathy, LV tumors, and $\mathrm{LV}$ aneurysms, ${ }^{21}$ the specific indications for dynamic cardiomyoplasty remain controversial. ${ }^{22}$ Chachques and associate ${ }^{23}$ have recommended dynamic cardiomyoplasty for patients in whom surgery has failed to improve cardiac function or for patients with coronary lesions that cannot be bypassed. A detailed analysis of the hemodynamic effects of this procedure on coronary blood flow has never been undertaken. Therefore, we tested the effect of dynamic cardiomyoplasty on coronary arterial blood flow to clarify whether application of this procedure for ischemic heart disease is beneficial.

In the present study, measurement of the coronary flow pattern with a $3 \mathrm{~F}$ Doppler catheter allowed signal analysis by the fast Fourier transformation analysis. ${ }^{24}$ Although an electromagnetic flow probe or ultrasonic crystals were applied for accurate measurement of the blood flow of the large coronary artery in dogs, ${ }^{25,26}$ both of them could not apply for the present study. Burst electrical stimuli by the cardiac stimulator would affect the electromagnetic flow probe on the large coronary artery, or crystal alignment would be changed during the contraction of latissimus dorsi muscle flap. Important advantages of this Doppler catheter system are its safety of positioning, stability of signals, accuracy of measurement, and easy transit through the major arteries of the coronary circulation. ${ }^{27,}{ }^{28}$ For accurate measurements of coronary blood flow or coronary blood flow velocity with this system, several variables must be known. These problems include the position of the ultrasonic flow probe with respect to the longitudinal axis of blood flow, the cross-sectional area of the blood vessel, and the constant position of the piezoelectric crystal relative to the blood vessel. ${ }^{29}$ In the present study, we fixed the Doppler catheter at the origin of the left anterior descending coronary 
Table II. Summarized data of the coronary blood flow velocity

\begin{tabular}{|c|c|c|c|c|c|c|}
\hline \multirow[b]{2}{*}{$D C M P$} & \multicolumn{3}{|c|}{ Systolic coronary flow } & \multicolumn{3}{|c|}{ Diastolic coronary flow } \\
\hline & $\begin{array}{c}\text { Peak velocity } \\
(\mathrm{cm} / \mathrm{sec})\end{array}$ & $\begin{array}{l}T V I \\
(\mathrm{~cm})\end{array}$ & $\begin{array}{l}\% S F \\
(\%)\end{array}$ & $\begin{array}{c}\text { Peak velocity } \\
(\mathrm{cm} / \mathrm{sec})\end{array}$ & $\begin{array}{l}T V I \\
(\mathrm{~cm})\end{array}$ & $\begin{array}{c}\% D F \\
(\%)\end{array}$ \\
\hline Off & $20.8 \pm 1.3$ & $2.1 \pm 0.3$ & $20.3 \pm 2.4$ & $33.5 \pm 3.4$ & $8.5 \pm 0.8$ & $79.7 \pm 2.4$ \\
\hline On & $25.9 \pm 1.5$ & $2.5 \pm 0.3$ & $22.0 \pm 3.1$ & $34.8 \pm 3.6$ & $9.4 \pm 1.0$ & $78.0 \pm 3.1$ \\
\hline Percent change & $26.9 \pm 6.5$ & $20.9 \pm 4.8$ & $8.3 \pm 4.9$ & $4.0 \pm 1.6$ & $10.0 \pm 4.6$ & $-2.1 \pm 1.4$ \\
\hline$p$ & $<0.005$ & 0.005 & NS & $<0.05$ & $<0.05$ & NS \\
\hline
\end{tabular}

All values are represented as mean \pm standard error of the mean. $D C M P$, Dynamic cardiomyoplasty; $T V I$, time-velocity integral; $\% S F$, percent systolic fraction; $\% D F$, percent diastolic fraction; percent change, changes from the unstimulated value. Statistical analysis by a paired $t$ test; $N S$, not significant.

artery inserted retrogradely through the first branch of the left descending artery and measured the blood velocity toward the catheter where muscular contraction may not affect the diameter of the vessels directly (see Fig. 2). We also controlled the distance between the catheter tip and sampling point where the Doppler signals were detected in each measurement to minimize the motion artifact.

Unlike other vascular beds, the singular attribute of left coronary flow is that $60 \%$ to $80 \%$ of left coronary inflow occurs in diastole. ${ }^{10} \mathrm{~A}$ low fraction of systolic flow reflects, first of all, the shorter duration of this phase of the cardiac cycle and, more important, the indirect effects, both restrictive and capacitative, of compressive forces exerted by myocardium surrounding the intramural coronary arteries. ${ }^{10}$ Systolic wave form in an epicardial coronary artery is the result of antegrade systolic flow impelled by coronary flow pressure, opposed by the retrograde flow of blood expressed from intramural vessels by the action of systolic intramyocardial pressure. At the onset of ventricular systole, coronary flow falls precipitously, and flow rate remains low throughout systole, tending to rise somewhat during midsystole and fall again at the end of this portion of the cardiac cycle (see Fig. 3). During myocardial relaxation at the end of systole, coronary flow rate rises rapidly to a zenith early in diastole and then falls as diastolic runoff from the root of the aorta lowers coronary perfusion pressure. Retarded myocardial relaxation, such as that brought about by ischemia, would be expected to reduce early diastolic acceleration of blood into the coronary arteries. ${ }^{10}$

In application of dynamic cardiomyoplasty, coronary flow could be affected by contraction of the skeletal muscle flap. In the systolic phase, the coronary artery could be compressed directly by the skeletal muscle flap. Systolic compression of the coronary arteries has been described in patients having a myocardial bridge ${ }^{30}$ or an epicardial tumor, ${ }^{31}$ in whom antegrade coronary flow was impeded by extraarterial vascular compression. In addition, diastolic coronary artery filling may be impaired by acute impairment of LV diastolic function after the operation of dynamic cardiomyoplasty. ${ }^{32}$ Incomplete relaxation of the skeletal muscle flap after systolic tetanic muscular contraction also could disturb early diastolic acceleration of blood into the coronary arteries. Incomplete relaxation of the LV may occur chronically because of thick adhesion between the skeletal muscle flap and epicardium impairing diastolic coronary artery filling and simulating the situation arising in constrictive pericarditis. $^{33,34}$

In some experimental studies, vascular anastomoses have been demonstrated to develop between the latissimus dorsi muscle graft and the myocardium. ${ }^{35}$ However, it has not yet been determined whether these anastomoses can provide any significant blood supply to the LV myocardium.

In the present study, epicardial coronary arterial blood flow velocity was significantly enhanced in both systole and diastole. Several factors influence coronary blood flow-physical factors, metabolic factors, humoral factors, and neural factors. ${ }^{9}$ In these factors, physical factors, the arterial pressure gradient (aortic-LV pressure) and the time spent in diastole, are the major determinants of coronary blood flow. However, excessively elevated pressure does not result in unneeded perfusion because of autoregulation. ${ }^{36}$ On the other hand, when the perfusion pressure is very low, the coronary circulation is maximally dilated and coronary blood flow is linearly related to the perfusion pressure., ${ }^{9,26,37}$ Dole and associates ${ }^{36}$ showed that autoregulation appeared when coronary artery pressure was between 75 and $125 \mathrm{~mm} \mathrm{Hg}$ and was totally abolished between 40 and $60 \mathrm{~mm} \mathrm{Hg.}{ }^{10}$ In the present study, mean aortic pressure without muscular assistance was low $(59.9 \pm 4.9 \mathrm{~mm} \mathrm{Hg})$ and then rose to $69.6 \pm 5.6$ $\mathrm{mm} \mathrm{Hg}$ as a result of contraction of latissimus dorsi muscle flap. Elevation of mean aortic pressure in the present study would be expected to be linearly correlated with increase of coronary blood flow ${ }^{9,36}$ and may have offset the potential reduction of coronary arterial blood flow due to extraarterial vascular compression. Our findings of the 
increase in coronary arterial blood flow velocity would be well associated with the enhancement of coronary blood flow during muscular assistance.

In the present study, a constrictive effect was not observed because severe adhesions were not present between the latissimus dorsi graft and the myocardium. Thus further long-term investigations of the effect of cardiomyoplasty on diastolic coronary arterial blood flow need to be undertaken.

Dynamic cardiomyoplasty remains an experimental operation. The initial experience with cardiomyoplasty has produced a higher than anticipated mortality. Furnary, ${ }^{4}$ Magovern,${ }^{38}$ and their associates showed the low operative mortality in patients with preserved right ventricular function ${ }^{4}$ and recommended that operative techniques be improved, that better methods for training and stimulating the muscle be developed, and that the indications and contraindications for the operation be further defined.$^{38}$ The results of this study suggest that dynamic cardiomyoplasty may not adversely affect coronary arterial blood flow when applied for ischemic myocardial failure.

We gratefully acknowledge our late Professor Emeritus Kazuo Nakamura, who showed the diaphragmatic graft to be a functioning substitute for the myocardium in 1964, for directing us in this study, and Dr. Sidney Levitsky, the Professor of Surgery at Harvard Medical School, Boston, Massachusetts, for critically reviewing the manuscript.

\section{RE F ER E N C ES}

1. Carpentier A, Chachques J. Myocardial substitution with a stimulated skeletal muscle: first successful clinical case [Letter]. Lancet 1985;1:1267.

2. Carpentier A, Chachques J. Clinical dynamic cardiomyoplasty: method and outcome. Semin Thorac Cardiovasc Surg 1991;3:136-9.

3. Moreira L, Stolf N, Bocchi E, et al. Latissimus dorsi cardiomyoplasty in the treatment of patients with dilated cardiomyoplasty. Circulation 1990;82(Suppl):IV257-63.

4. Furnary A, Magovern J, Christlieb I, Orie J, Simpson K, Magovern G. Clinical cardiomyoplasty: preoperative factors associated with outcome. Ann Thorac Surg 1992;54: 1139-43.

5. Orie J. Dynamic cardiomyoplasty: a possible alternative treatment of congestive heart failure. Semin Thorac Cardiovasc Surg 1991;3:98-100.

6. Magovern G, Heckler F, Park S, et al. Paced skeletal muscle for dynamic cardiomyoplasty. Ann Thorac Surg 1988;45:614-9.

7. Jatene A, Moreira L, Stolf N, et al. Left ventricular function changes after cardiomyoplasty in patient with dilated cardiomyoplasty. J THORAC CARDIOVASC SURG 1991;102: 132-9
8. Lee K, Dignan R, Dyke C, et al. Effects of dynamic cardiomyoplasty on left ventricular performance and myocardial mechanics in dilated cardiomyopathy. J THORAC CARDIOVASC SuRG 1991;102:124-31.

9. Braunwald E. Coronary circulation. In: Braunwald E, ed. Heart disease. 4th ed. Philadelphia: WB Saunders, 1992 55-8.

10. Olsson R, Bunger R, Spaan J. Coronary circulation. In: Fozzard H, Haber E, Jennings R, Katz A, Morgan H, eds. The heart and cardiovascular system. 2nd ed. New York: Raven Press, 1991:1393-1425.

11. Kantrowitz A, Mckinnon W. The experimental use of the diaphragm as an auxillary myocardium.Surg Forum 1959; 9:266-8.

12. Nakamura K, Glenn W. Graft of diaphragm as a functioning substitute for myocardium: an experimental study. J Surg Res 1964;4:435-9.

13. Salmons S, Sreter F. Significance of impulse activity in the transformation of skeletal muscle type. Nature 1976;263: 30-4.

14. Salmons $S$, Henriksson J. The adaptive response of skeletal muscle to increase use. Muscle Nerve 1981;4:94-105.

15. Dewar M, Drinkwater D, Wittnich C, Chiu R. Synchronously stimulated skeletal muscle graft for myocardial repair: an experimental study. J THORAC CARDIOVASC SuRG 1984;87:325-31.

16. Pette D, Vrbova G. Neural control of phenotypic expression in mammalian fibers. Muscle Nerve 1985;8:676-89.

17. Hagege A, Fernandez F, Denos M, Guerot C, Chachques J, Carpentier A. Hemodynamic study of long-term efficiency of dynamic cardiomyoplasty: preliminary results. Circulation 1988;78(Suppl):II345.

18. Anderson W, Anderson J, Acker M, et al. Skeletal muscle grafts applied to the heart. Circulation 1988;78(Suppl):III180-90.

19. Chagas A, Moreira L, da Luz P, et al. Stimulated preconditioned skeletal muscle cardiomyoplasty: an effective means of cardiac assist. Circulation 1989;80(Suppl):III202-8.

20. Kao R, Christlieb I, Magovern G, Park S, Magovern G. The importance of skeletal muscle fiber orientation for dynamic cardiomyoplasty. J ThoraC Cardiovasc SurG 1990;99:134-40.

21. Magovern G. Invited commentary. Cardiomyoplasty does not preclude heart transplantation. Ann Thorac Surg 1992;53:880-1.

22. Hill A, Chiu R. Dynamic cardiomyoplasty for treatment of heart failure. Clin Cardiol 1989;12:681-8.

23. Chachques J, Grandjean P, Schwartz K, et al. Effect of latissimus dorsi dynamic cardiomyoplasty on ventricular function. Circulation 1988;78(Suppl):III203-16.

24. Kitabatake A, Tanouchi J, Ishihara K, et al. Quantitative assessment of coronary artery flow by Doppler catheter using fast Fourier spectrum analysis. Jpn J Med Ultrason 1988;15(Suppl II):325-6.

25. Vatner S, Pagani M, Manders W, Pasipoularides A. Alpha 
adrenergic vasoconstriction and nitroglycerin vasodilatation of large coronary arteries in the conscious dog. J Clin Invest 1980;65:5-14.

26. Tomoike H, Ootsubo H, Sakai K, Kikuchi Y, Nakamura M. Continuous measurement of coronary artery diameter in situ. Am J Physiol 1981;240:H73-9.

27. Sibley D, Millar H, Hartley C, Whitlow P. Subselective measurement of coronary blood flow velocity using a steerable Doppler catheter. J Am Coll Cardiol 1986;8:1332-40.

28. Tadaoka S, Kagiyama M, Hiramatsu O, et al. Accuracy of 20-MHz Doppler catheter coronary artery velocimetry for measurement of coronary blood flow velocity. Cathet Cardiovasc Diagn 1990;19:205-13.

29. Chilian W, Layne S. Ultrasonic measurements of coronary blood flow. In: Kaziya F, Klassen G, Spaan J, Hoffman J, eds. Coronary circulation. Tokyo: Springer-Verlag, 1990: 55-72.

30. Noble J, Bouryssa M, Petitclerc R, Dyrda I. Myocardial bridging and milking effect of the left anterior descending coronary artery: normal variant or obstruction? Am J Cardiol 1976;37:993-9.

31. Radwaner B, Geringer R, Goldmann A, Schwartz M,
Kemp H. Left main coronary artery stenosis following mediastinal irradiation. Am J Med 1987;82:1017-20.

32. Corin W, George D, Sink J, Santamore W. Dynamic cardiomyoplasty acutely impairs left ventricular diastolic function. J ThoraC CARDIOvasc SuRg 1992;104:1662-71.

33. Goldverg E, Stein J, Berger M, Berdoff R. Diastolic segmental coronary artery obliteration in constrictive pericarditis. Cathet Cardiovasc Diagn 1981;7:197-202.

34. Navetta F, Barber M, Gurbel P, et al. Myocardial ischemia in constrictive pericarditis. Am Heart J 1988;116:110711.

35. Christ J, Spira M. Application of latissimus dorsi muscle to the heart. Ann Plast Surg 1982;8:118-21.

36. Dole W, Yamada N, Bishop V, Olsson R. Role of adenosine in coronary blood flow regulation after reductions in perfusion pressure. Circ Res 1985;56:517-24.

37. Bellamy R. Diastolic coronary artery pressure-flow relations in the dog. Circ Res 1978;43:92-101.

38. Magovern J, Furnary A, Christlieb I, Kao R, Park S, Magovern G. Indications and risk analysis for clinical cardiomyoplasty. Semin Thorac Cardiovasc Surg 1991;3:1458 .

\section{Bound volumes available to subscribers}

Bound volumes of THE JOURNAL OF THORACIC AND CARDIOVASCULAR SURGERY are available to subscribers (only) for the 1994 issues from the Publisher, at a cost of $\$ 82.50$ for domestic, $\$ 106.28$ for Canadian, and $\$ 100.50$ for international subscribers for Vol. 107 (January-June) and Vol. 108 (July-December). Shipping charges are included. Each bound volume contains a subject and author index and all advertising is removed. Copies are shipped within 60 days after publication of the last issue of the volume. The binding is durable buckram with the JOURNAL name, volume number, and year stamped in gold on the spine. Payment must accompany all orders. Contact Mosby-Year Book, Inc., Subscription Services, 11830 Westline Industrial Drive, St. Louis, Missouri 63146-3318, USA; phone 1 (800) 4534351 or (314) $453-4351$.

Subscriptions must be in force to qualify. Bound volumes are not available in place of a regular JourNaL subscription. 